\title{
Untersuchungen über die Bindung einer Fraktion aus menschlichem Ig-G-Globulin an die Membran von L-Zellen, Zajdela- und Yoshida-Asciteszellen
}

\author{
H. von Boehmer, V. Gladigau, Renate Bayer und G. Ruhenstroth-Bauer
}

\author{
Max-Planck-Institut für Biochemie, München (Direktor: Professor Dr. A ButenandT) \\ (Z. Naturforschg. 24 b, 1026-1031 [1969]; eingegangen am 8. April 1969)
}

\begin{abstract}
1. Eine menschliche Ig-G-Globulin-Fraktion $\left(\mathbf{A}_{1} \mathbf{F}_{1}\right)$ setzt die elektrophoretische Beweglichkeit von L-Zellen, Yoshida- und Zajdela-Hepatom-Asciteszellen herab. Diese Wirkung kann durch Waschen mit physiologischer Kochsalzlösung rückgängig gemacht werden.

2. Eine Erhöhung der Ionenstärke geht mit einer Verringerung der Wirkung von $\mathbf{A}_{1} \mathrm{~F}_{1}$ auf die Zellmembran einher; bei $\mu=0,15$ ist keine Wirksamkeit nachweisbar. Die Art der von uns untersuchten Ionen spielt hierbei keine Rolle. In Verbindung mit einer zweiten Serumfraktion $A_{2} F_{1}$ ist jedoch $A_{1} F_{1}$ bei $\mu=0,15$ voll wirksam. Bei Humanserum ist der Effekt der Ionenstärke nicht nachweisbar, obwohl auch bei der Inkubation der Zellen im Humanserum die Membranwirkung durch die Ig-G-Globulin-Fraktion verursacht wird.

3. Bei der elektrophoretischen Membranaktivität des Ig-G-Globulins $\left(A_{1} F_{1}\right)$ handelt es sich nicht um eine Anlagerung eines spezifischen Antikörpers. Die Beteiligung der C'lq-Komponente des Komplementsystems konnte ausgeschlossen werden.
\end{abstract}

L-Zellen, Zajdela- und Yoshida-Hepatom-Asciteszellen werden durch menschliches Serum in ihrer elektrophoretischen Beweglichkeit verlangsamt. Bei L-Zellen sind hierfür bestimmte Ig-G-Globuline verantwortlich ${ }^{1}$. Die Wirkung des Humanserums kann durch einmaliges Waschen der Zellen mit physiologischer Kochsalzlösung beseitigt werden, während bei einem M i c h a e l i s - Sorbit-Puffer der Ionenstärke $\mu=0,03$ der elektrophoretische Effekt des Serums erst nach längerem Waschen rückgängig gemacht wird. Bei einer Ionenstärke $\mu=0,15$ führt nur die Kombination zweier durch Chromatographie an DEAE-Sephadex trennbarer Serumfraktionen $A_{1} F_{1}$ und $\mathrm{A}_{2} \mathrm{~F}_{1}$ zur Verringerung der elektrophoretischen Beweglichkeit von L-Zellen; die Fraktion $\mathrm{A}_{1} \mathrm{~F}_{1}$ stellt immunelektrophoretisch reines Ig-G-Globulin dar, $\mathrm{A}_{2} \mathrm{~F}_{1}$ wurde zwar immunelektrophoretisch nicht völlig einheitlich gewonnen, enthält jedoch ebenfalls überwiegend Ig-G-Globulin ${ }^{1}$.

Die folgenden Untersuchungen beschäftigen sich mit dem Einfluß von Ionenstärke und Ionenart auf die Wirkung von immunelektrophoretisch reinem Ig-G-Globulin und Humanserum auf die elektrophoretische Beweglichkeit der genannten Zellarten, und damit mit der Spezifität der Bindung von Serumproteinen an die Zellmembran.

1 R. Arnold, H. v. Boehmer u. G. Ruhenstroth-Bauer, Exp. Cell Res. 50, 562 [1968].

2 G. F. Fuhrmann u. G. Ruhenstroth-Bauer, in: Cell Electrophoresis, ed. by J. A. Churchill, Ltd., London 1965.

3 E. Bey, Inaug. Dissertation, Univ. München 1964.

${ }^{4}$ Documenta Geigy, Wissenschaftliche Tabellen p. 274 (1968).

\section{Methoden}

Zellelektrophorese: Die Untersuchungen erfolgten mit der von der Fa. C. Zeiss (Oberkochen) hergestellten Apparatur 2, 3 . Es wurde die Zeit gemessen, die die Zellen bei einer Stromstärke von $3 \mathrm{~mA}$ benötigten, um eine Wegstrecke von $130 \mu$ zurückzulegen. Das Meßgut wurde in Michaelis-Sorbit-Puffer (MSP) aufgeschwemmt: M i ch a el is - Puffer ${ }^{4}$ : A: 1/7 M Natriumacetat $+1 / 7 \mathrm{M}$ Veronalnatrium in bidest. Wasser, B : $0,1 \mathrm{~N}$ Salzsäurelösung. C: $50 \mathrm{ml} \mathrm{A}+60 \mathrm{ml} \mathrm{B}+20 \mathrm{ml}$ 8,5-proz. NaCl-Lösung $+140 \mathrm{ml} \mathrm{CO} 2$ freies bidest. Wasser.

M i c h a e li s-Sorbit-Puffer: 4 Vol. 1/3 M SorbitolLösung +1 Vol. M i cha el is-Puffer. Ionenstärke $\mu=0,03$, spez. Widerstand bei der Meßtemperatur von $23^{\circ} \varrho=340 \Omega \mathrm{cm}, \mathrm{pH} 7,0$.

Zellen: L-Zellen ${ }^{5}$, Yoshida- ${ }^{6}$ und Zajdela ${ }^{7}$-Asciteszellen wurden wie angegeben ${ }^{1}$ gezüchtet und zur Inkubation vorbereitet.

Präparation von Ig-G-Globulin: Humanserum von klinisch gesunden Spendern wurde mit einer bei $4^{\circ} \mathrm{zu}$ $80 \%$ gesättigten Ammonsulfat-Lösung ${ }^{8}$ bei $40 \%$ Sättigung gefällt. Der Niederschlag $\left(A_{1}\right)$ wurde $24 \mathrm{Stdn}$. gegen bidest. Wasser dialysiert und anschließend friergetrocknet. 2,5 g des Trockengutes wurden über DEAESephadex chromatographiert (Säule: 2,5.30 cm; Elutionsgeschwindigkeit: $20 \mathrm{ml} /$ Stde.; Elutionspuffer: $0,01 \mathrm{M}$ Phosphat, $\mathrm{pH} 7,0)$. Unter diesen Elutionsbedingungen erhielten wir einen Gipfel $\left(A_{1} F_{1}\right)$, der erneut 24 Stdn. gegen bidest. Wasser dialysiert und anschlie-

5 W. R. J. Earle, Nat. Cancer Inst. 4. 165 [1943].

6 T. Yoshida, Gann 40, 1 [1949].

7 R. Monier, P. Zajdela, P. Chaix u. J. F. Petit, Cancer Res. 19, 927 [1959].

8 P. STelos, in: Handbook of Exp. Immunology, ed. by D. M. WeIr, Blackwell Scientific Publications, Oxford a. Edinburgh 1967, p. 5. 
Bend lyophilisiert wurde. Das Ergebnis der immunelektrophoretischen Untersuchung dieser Fraktion zeigt Abb. 1.

a)

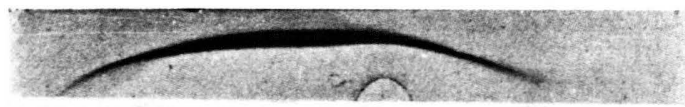

b)

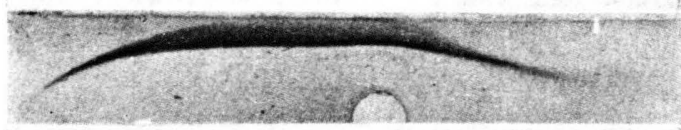

c)

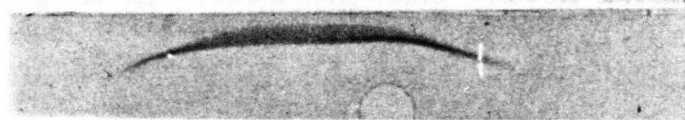

d)

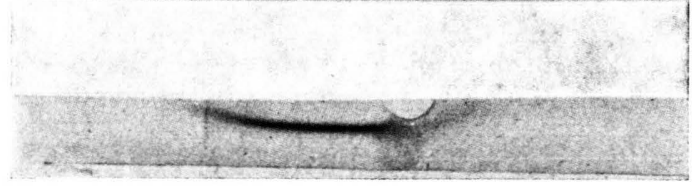

Abb. 1. Immunelektrophorese der membranaktiven Fraktion $A_{1} F_{1}$, a) 1-proz. $A_{1} F_{1}$-Lösung, Antihumanserum; b) 1-proz. $\mathrm{A}_{1} \mathrm{~F}_{1}$-Lösung, Antihumanserum: physiologische Kochsalzlösung $=1: 1 ;$ c) 0,1-proz. $A_{1} F_{1}$-Lösung, Antihumanserum; d) 0,01-proz. $\mathrm{A}_{1} \mathrm{~F}_{1}$-Lösung, Antihumanserum.

Immunelektrophorese: Die Immunelektrophorese erfolgte mit der Desaga-Ugi-Einheit (Desaga G.m.b.H. Heidelberg). Die Proben wurden in 1,5-proz. AgaroseGel in Veronal-Acetat-Puffer $\mathrm{pH} \mathrm{8,6}{ }^{9}$ über eine Distanz von $9 \mathrm{~cm}$ getrennt. Humanantiserum vom Kaninchen: Behringwerke A.G. (Marburg).

Gewinnung von $\mathrm{H}$ - und L-Ketten ${ }^{10,11}$ : eine 2-proz. Lösung von $\mathrm{A}_{1} \mathrm{~F}_{1}$ in 0,55 $\mathrm{M}$ Tris-HCl-Puffer ( $\left.\mathrm{pH} 8,2\right)$ wurde mittels Wasserstrahlpumpe entgast. Bei $4^{\circ}$ wurde die Lösung langsam mit Stickstoff durchströmt. Die Reduktion erfolgte durch Zusatz von Mercaptoäthanol zur Endkonzentration 0,75 M. Nach einer Stde.
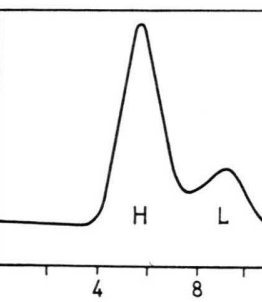

Abb. 2. Verlauf der Proteinkonzentration nach Chromatographie von reduziertem und alkyliertem $A_{1} F_{1}$ über DEAESephadex.

9 P. Grabar u. G. A. Williams, Biochim. biophysica Acta [Amsterdam] 10, 193 [1953].

10 D. R. Stanworth u. G. J. Pordoe, in: Handbook of Exp. Immunology, ed. by D. M. WeIR, Blackwell Scientific Publications, Oxford a. Edinburgh 1967, p. 168 wurde bei $0^{\circ}$ mit einem gleichen Volumen einer $0,75 \mathrm{M}$ Jodacetamid-Lösung in Tris-HCl-Puffer alkyliert. Nach einer weiteren Stunde wurde die Lösung 24 Stdn. gegen $1 \mathrm{~N}$ Essigsäure dialysiert und anschließend auf die Hälfte des Volumens eingeengt. $15 \mathrm{ml}$ dieser Lösung wurden über Sephadex G-75 (Säule: $3 \cdot 70 \mathrm{~cm}$ ) mit $1 \mathrm{~N}$ Essigsäure chromatographiert. Den Verlauf der Proteinkonzentration im Eluat zeigt Abb. 2. Der dritte Gipfel enthält kein Protein, sondern Jodacetamid, dessen Absorptionsmaximum bei $270 \mathrm{~m} \mu$ liegt ${ }^{12}$. Die $\mathrm{H}$ - und die L-Fraktion wurden 24 Stdn. gegen Acetatpuffer $(\mathrm{pH}$ $5,4)^{4}$ dialysiert und eingeengt. Die Endproteinkonzentration betrug $40 \mathrm{mg} / \mathrm{ml}$. Auf diese Weise konnte ein Proteinausfall vermieden werden.

Diagramme: Die Diagramme wurden aus Versuchsansätzen mit einheitlichen Zellchargen gewonnen.

\section{Ergebnisse}

Etwa $1,5 \cdot 10^{6}$ L-Zellen, Yoshida- oder ZajdelaHepatom-Asciteszellen wurden mit $2 \mathrm{ml}$ einer 1-proz. Lösung von $\mathrm{A}_{1} \mathrm{~F}_{1}$ in MSP $30 \mathrm{Min}$. bei $37^{\circ}$ inkubiert. Nach der Inkubation wurden die Zellen bei $250 \mathrm{~g}$ $3-5$ Min. a) 3-mal mit je $10 \mathrm{ml}$ MSP und b) 2 -mal mit physiologischer Kochsalzlösung und 1-mal mit MSP gewaschen.

Alle drei Zellarten werden durch $A_{1} F_{1}$ in ihrer elektrophoretischen Beweglichkeit verlangsamt. Das Waschen mit physiologischer Kochsalzlösung verringert den Effekt stärker als das Waschen mit MSP (Abb. 3).
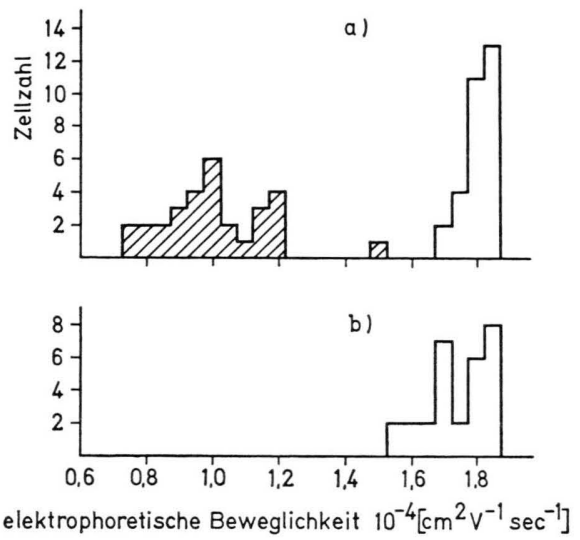

Abb. 3. Elektrophoretische Beweglichkeit von Yoshida-Hepatom-Asciteszellen nach a) Inkubation in einer 1-proz. $A_{1} F_{1}$. Lösung in physiologischer Kochsalzlösung $\square$ und in MSP . Beide Ansätze wurden nach Inkubation 3-mal mit MSP gewaschen. b) Inkubation in einer 1-proz. $A_{1} F_{1}$-Lösung in MSP; der Ansatz wurde 2-mal mit physiologischer Kochsalzlösung, danach 1-mal mit MSP gewaschen.

11 J. B. Fleischmann, R. H. Pain, and K. R. Porter, Arch. Biochem. biophysics Suppl. 1, 174 [1962].

12 Organic Electronic Spectral Data Vol. IV (1958-1959) ed. by J. P. Philipps and F. C. NACHOD, Interscience publishers, New York. 
Je $1,5 \cdot 10^{6}$ L-Zellen wurden mit $2 \mathrm{ml}$ 1-proz. $\mathrm{A}_{1} \mathrm{~F}_{1}$ enthaltender 0,3 osmolarer NaCl-, KCl-, KBr-, Glucose- und MSP-Lösung $30 \mathrm{Min}$. bei $37^{\circ}$ inkubiert und 2-mal mit je $10 \mathrm{ml}$ MSP gewaschen. Bei Lösungen der Ionenstärke 0,15 ist $A_{1} F_{1}$ deutlich geringer aktiv (Abb. 4).
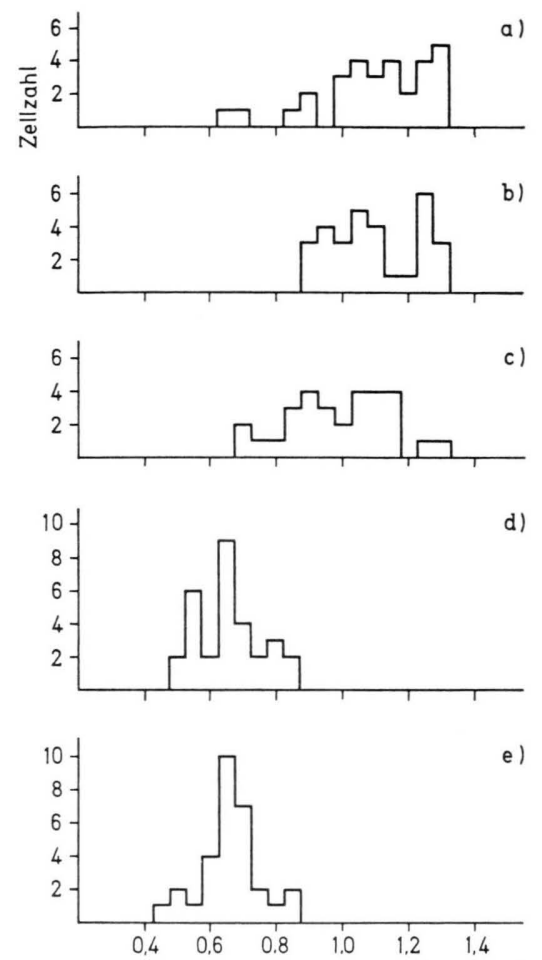

elektrophoretische Beweglichkeit $10^{-4}\left[\mathrm{~cm}^{2} \mathrm{v}^{-1} \mathrm{sec}^{-1}\right]$

Abb. 4. Elektrophoretische Beweglichkeit von L-Zellen nach Inkubation in 0,3 osmolaren Lösungen von a) $\mathrm{KBr}, \mathrm{b}) \mathrm{KCl}$, c) $\mathrm{NaCl}$, d) Glucose, e) $\mathrm{MSP}$, die jeweils $0,1 \% \mathrm{~A}_{1} \mathrm{~F}_{1}$ enthielten.

Werden $20 \mathrm{mg} \mathrm{A} \mathrm{A}_{1} \mathrm{~F}_{1}$ in $2 \mathrm{ml}$ dest. Wasser gelöst, gegen physiologische Kochsalzlösung dialysiert und anschließend mit $1,5 \cdot 10^{6}$ L-Zellen inkubiert, tritt ebenfalls eine Verringerung der Membranaktivität im Vergleich zu $A_{1} F_{1}$ auf, welches gegen MSP dialysiert wurde. Eine Rückdialyse gegen eine Außenphase der Ionenstärke $\mu=0,03$ führt wieder zur vollen Wirksamkeit.

20, 40, 60 und $100 \mathrm{mg} A_{1} F_{1}$ wurden jeweils in $2 \mathrm{ml}$ physiologischer Kochsalzlösung bzw. MSP gelöst und mit je $1,5 \cdot 10^{6} \mathrm{~L}$-Zellen $30 \mathrm{Min}$. bei $37^{\circ}$ inkubiert. Die Zellen wurden 2-mal mit je $100 \mathrm{ml}$ MSP gewaschen. Die elektrophoretischen Beweglichkeiten der Zellen zeigt Abb. 5.

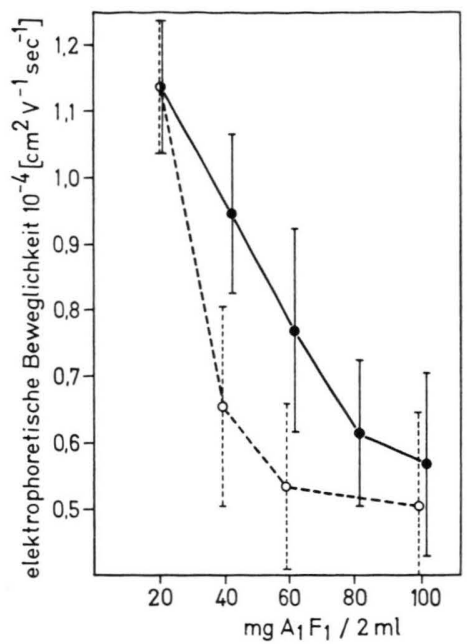

Abb. 5. Elektrophoretische Beweglichkeit von L-Zellen in Abhängigkeit von der $\mathrm{A}_{1} \mathrm{~F}_{1}$-Konzentration der Inkubationslösun-

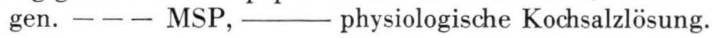

In zwei Versuchen wurde menschliches Serum 24 Stdn. a) gegen physiologische Kochsalzlösung und b) gegen MSP dialysiert. Im Test an L-Zellen ist die Membranaktivität gegenüber nichtdialysiertem Serum bei Ansatz a) etwas erhöht, während sie bei Ansatz b) nach Abzentrifugieren des Niederschlages in einem Fall schwach erhöht, im anderen dagegen verringert ist. Im Beispiel der Abb. 6 betrug der spezifische Widerstand des Serums bei $23^{\circ}$ vor der Dialyse: $\varrho=88,1 \Omega \mathrm{cm}$; nach Dialyse a) gegen phy-
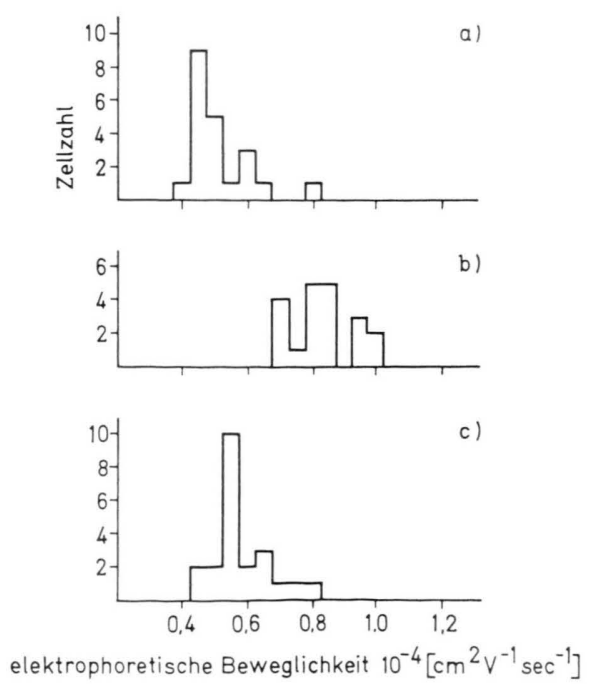

Abb. 6. Elektrophoretische Beweglichkeit von L-Zellen. Inkubation in Serum nach Dialyse gegen a) physiologische Kochsalzlösung, b) MSP, c) Inkubation in nicht-dialysiertem Serum. 
siologische Kochsalzlösung: $\varrho=78,7 \Omega \mathrm{cm}$ und b) gegen MSP : $\varrho=388,6 \Omega \mathrm{cm}$.

Bei $A_{1}$, dem Niederschlag einer Ammonsulfatfällung bei $40 \%$ Sättigung, zeigte sich nach Dialyse gegen physiologische Kochsalzlösung keine geringere Aktivität als bei $A_{1}$, das gegen MSP dialysiert wurde (Abb. 7).

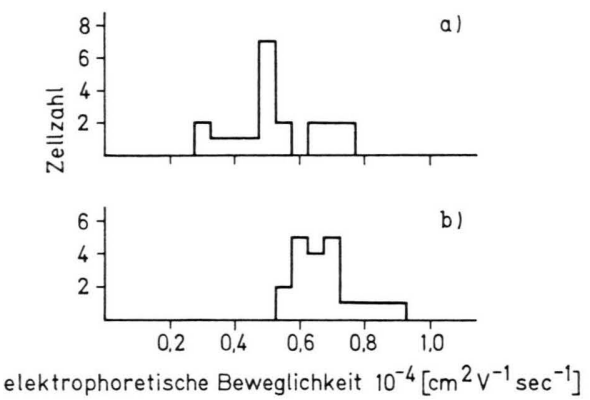

Abb. 7. Elektrophoretische Beweglichkeit von L-Zellen. Inkubation in 2,5-proz. $A_{1}$-Lösung nach Dialyse gegen a) physiologische Kochsalzlösung, b MSP.

Die Wirkung von Humanserum und $A_{1} F_{1}$ unterscheidet sich auch in der Thermolabilität. Erhitzt man $20 \mathrm{mg} \mathrm{A}_{1} \mathrm{~F}_{1}$ in $2 \mathrm{ml}$ MSP $30 \mathrm{Min}$. auf $60^{\circ}$, tritt eine Trübung auf. Bei $10000 \mathrm{~g}$ läßt sich kein Niederschlag abzentrifugieren. Werden nun L-Zellen mit diesem Ansatz inkubiert, ist gegenüber einem nicht erhitzten Kontrollansatz kein Aktivitätsverlust zu beobachten, während beim Erhitzen von Humanserum nach Abzentrifugieren des Niederschlages ein deutlicher Aktivitätsverlust zu finden ist (Abb. 8).

Daß jedoch auch im Humanserum bestimmte Ig-G-Globuline für die elektrophoretische Verlangsamung von Zellen verantwortlich sind, macht folgender Versuch wahrscheinlich:

L-Zellen und Zajdela-Asciteszellen wurden im Überschuß zu je $45 \mathrm{ml}$ Citraplasma gegeben und 30 Min. bei $37^{\circ}$ inkubiert. Anschließend wurde 2 -mal mit je $300 \mathrm{ml}$ MSP 10 Min. bei $250 \mathrm{~g}$
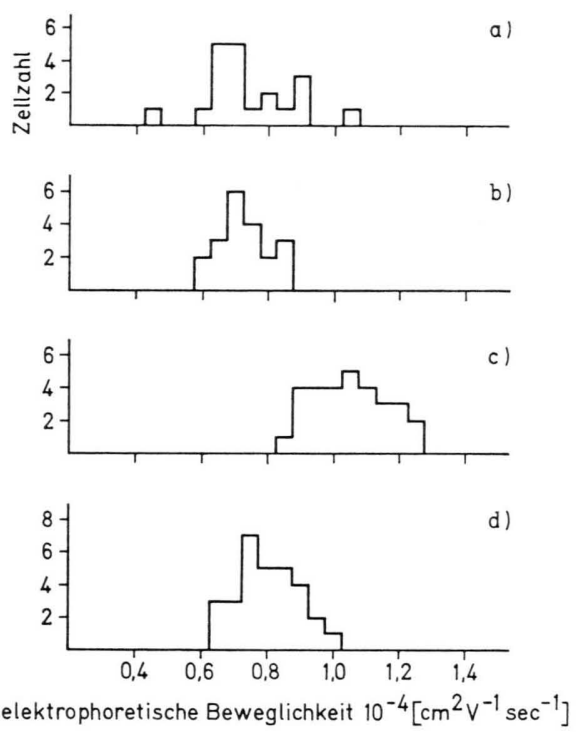

Abb. 8. Elektrophoretische Beweglichkeit von L-Zellen. Inkubation in a) $1 \% \mathrm{~A}_{1} \mathrm{~F}_{1}$ enthaltender MSP-Lösung, die $30 \mathrm{Min}$. auf $60^{\circ}$ erhitzt worden war; b) 1-proz. Lösung von $A_{1} F_{1}$ in MSP; c) 30 min. auf $60^{\circ}$ erhitztem Humanserum, d) Humanserum.

gewaschen. Dann wurde 1-mal mit $10 \mathrm{ml}$ physiologischer Kochsalzlösung gewaschen, der Überstand $24 \mathrm{Stdn}$. gegen bidest. Wasser dialysiert und danach lyophilisiert. Das Trockengut wurde in $1 \mathrm{ml}$ physiologischer Kochsalzlösung aufgefangen und immunelektrophoretisch untersucht (Abb.9). Bei Inkubation mit Humanserum reichert sich demnach vorwiegend Ig-G-Globulin an der Zelloberfläche an, es sind jedoch auch Banden anderer Proteine nachzuweisen.

Die Sedimentationskonstante $\mathrm{S}$ von $\mathrm{A}_{1} \mathrm{~F}_{1}$ wurde in einer 1-proz. Lösung des Proteins in physiologischer Kochsalzlösung $(\mathrm{pH} 7,0)$ gemessen; sie wurde auf $\mathrm{H}_{2} \mathrm{O}$ und Proteinkonzentration 0 umgerechnet ${ }^{13}$ und beträgt 6,06 .

Je $40 \mathrm{mg}$ der reduzierten und alkylierten Spaltprodukte von Ig-G-Globulin, H- und L-Ketten, gelöst a)

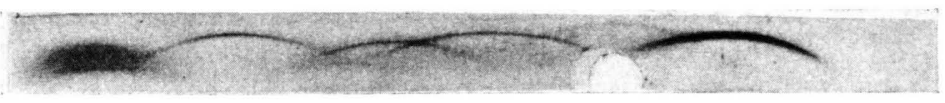

b)

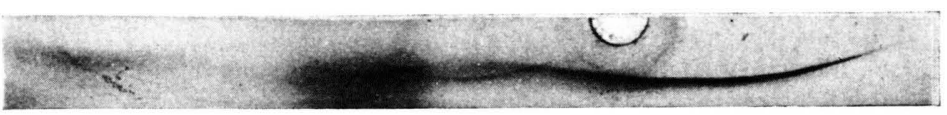

Abb. 9. Immunelektrophoretische Untersuchung der letzten Waschflüssigkeit von a) Zajdela-Asciteszellen, b) L-Zellen, die mit Citratplasma inkubiert, dann mit MSP und schließlich mit physiologischer Kochsalzlösung gewaschen worden waren.

13 H. E. Schultze and J. F. Heremans, Molecular Biology of Human Proteins, Vol. 1, Elsevier publishing Comp. New York 1966, p. 222. 
in $3 \mathrm{ml}$ Acetatpuffer ( $\mathrm{pH} 5,2$ ) wurden mit L-Zellen 30 Min. bei $37^{\circ}$ inkubiert. Die L-Zellen wurden anschließend 2-mal mit $10 \mathrm{ml}$ MSP gewaschen. Zur Kontrolle wurden L-Zellen mit Acetatpuffer bei $37^{\circ}$ inkubiert. Sowohl H- als auch L-Ketten führen zu einer Verringerung der elektrophoretischen Beweglichkeit der Zellen (Abb. 10). Der Kontrollansatz zeigt bei der elektrophoretischen Untersuchung keine Abweichung gegenüber L-Zellen, die in physiologischer Kochsalzlösung $(\mathrm{pH} 7,0)$ inkubiert worden waren.

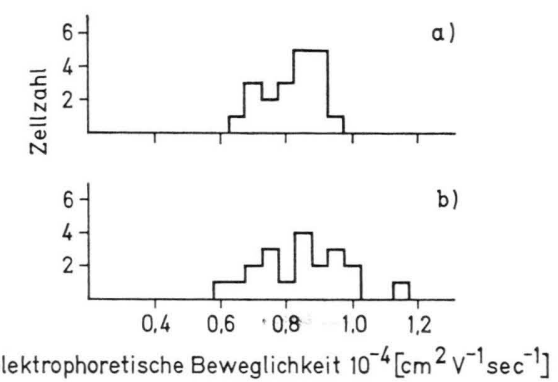

Abb. 10. Elektrophoretische Beweglichkeit von L-Zellen. In-

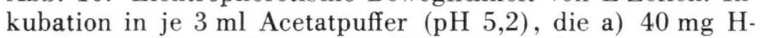
Ketten, b) 40 mg L-Ketten enthielten.

\section{Besprechung}

Die elektrophoretische Beweglichkeit von L-Zellen, Yoshida- und Zajdela-Hepatom-Ascites-Zellen wird durch Adsorption von Protein aus einer Ig-G-Globulinfraktion $\mathrm{A}_{1} \mathrm{~F}_{1}$ an die Zelloberfläche verlangsamt. Eine Anreicherung von Ig-G-Globulin an die Erythrozytenmembran beobachten MÜller und GramLICH ${ }^{14-16}$ und ARKY et al. ${ }^{17}$. Durch Waschen mit physiologischer Kochsalzlösung wird die elektrophoretisch erfaßbare Membranwirkung von $\mathrm{A}_{1} \mathrm{~F}_{1}$ wieder beseitigt; sie ist auch bei hoher Ionenstärke des Inkubationsmediums wesentlich geringer als bei niedriger Ionenstärke. Der Einfluß der Ionenstärke ist bei den untersuchten Salzlösungen von der Art der Ionen unabhängig. COLTEN et al. ${ }^{18,19}$ konnten beim Anstieg der Ionenstärke von $\mu=0,15$

14 H. E. Müller u. F. Gramlich, Hoppe-Seyler's Z. physiol. Chem. 334, 103 [1963].

15 H. E. Müller u. F. Gramlich, Experientia [Basel] 19, 571 [1963].

16 F. Gramlich u. H. E. Müller, Acta haematol. 30, 236 [1963].

17 J. Arky, I. Szaśz, E. Puskaś, G. A. Medgyesi u. I. GerGELY, Haematol. 2, 175 [1968].

18 H. R. Colten, T. Borsos, and H. I. Rapp, J. Immunolgy 100, 808 [1968]. auf $\mu=0,9$ einen Aktivitätsverlust der Komponente C'lq des Komplementsystems ${ }^{20}$ bei sensibilisierten Schaferythrozyten beobachten, der mit einer Änderung der Sedimentationskonstanten $S$ verbunden war; bei $\mu=0,15$ zeigt C'lq die Sedimentationskonstante $11 S$. Bei dieser Ionenstärke fanden wir jedoch für $\mathrm{A}_{1} \mathrm{~F}_{1}$ einen Wert von 6,06 S. Ferner konnten wir nach Ammonsulfatfällung des Serums und Abzentrifugieren der Euglobuline im Überstand Aktivität finden. Schließlich ist $\mathrm{A}_{1} \mathrm{~F}_{1}$ hitzestabil. Auf Grund dieser 3 Befunde scheidet die Нypothese ${ }^{21}$ aus, daß erst die Bindung von C'lq an einen spezifischen Antikörper, der selbst nicht elektrokinetisch wirksam ist, zur Verlangsamung der L-Zellen führt. Damit wird aber die Annahme einer Bindung eines zellspezifischen Antikörpers als Grund der elektrophoretischen Wirksamkeit unwahrscheinlich. Auch die Tatsache, daß sowohl H- als auch L-Ketten des Ig-G-Globulins eine Verlangsamung der elektrophoretischen Beweglichkeit der L-Zellen herbeiführen und die Wirkung des Serums durch Waschen mit physiologischer Kochsalzlösung rückgängig gemacht werden kann, spricht gegen diese Annahme ${ }^{22,}{ }^{23}$.

Eine Änderung der Ionenstärke wirkt sich auf die Membranaktivität des Serums anders als auf die einer Lösung von $A_{1} F_{1}$ aus. Dieser Unterschied könnte durch Proteine, die bei niedriger Ionenstärke im Serum ausfallen, hervorgerufen werden. Bei der Dialyse von $\mathrm{A}_{1}$ gegen MSP fällt jedoch kein Protein aus; trotzdem unterscheidet sich eine gegen physiologische Kochsalzlösung dialysierte $\mathrm{A}_{1}$-Fraktion nicht von einer, die gegen MSP dialysiert wurde.

MÜller und Gramlich ${ }^{15}$ berichten, daß sich an der Oberfläche von Erythrozyten ein Film aus mehreren, immunelektrophoretisch unterscheidbaren Proteinen bildet. Wenn dies auch bei den von uns untersuchten Zellen der Fall ist, könnte der unterschiedliche Effekt der Ionenstärke bei der Wirksamkeit des Serums und $A_{1}$ einerseits und einer 0,9-proz. Kochsalzlösung, die reines Ig-G-Globulin $\left(\mathrm{A}_{1} \mathrm{~F}_{1}\right)$ in Serumkonzentration enthält, andererseits folgendermaBen erklärt werden: Bei der isolierten wirksamen

${ }^{19}$ H. R. Colten, T. Borsos, and H. I. Rapp, J. Immunology 100, 799 [1968].

20 H. I. Müller-Eberhard u. H. G. Kunkel, Proc. Soc. exp. Biol. Med. (NY) 106, 291 [1961].

21 H. I. Müller-Eberhard, in: Immunchemie, Springer-Verlag, Berlin 1965, p. 309.

22 J. A. Forrester, D. C. Dumonde u. E. J. Ambrose, Immunology 8, 37 [1965].

23 G. M. Edelman, D. E. Olins, J. A. Gally u. N. D. Zinder, Proc. nat. Acad. Sci. USA 50, 4, 753 [1963]. 
Ig-G-Globulin-Fraktion $A_{1} F_{1}$ erschwert die zwischen Protein und Ionen des Lösungsmittels auftretende Wechselwirkung eine Adsorption an die Zellmembran ${ }^{24}$. Im Serum treten dagegen andere Proteine, die selbst die elektrophoretische Beweglichkeit der Zellen nicht beeinflussen, in diese Wechselbeziehungen ein und verhindern so die Salzwirkung. Dementsprechend ${ }^{1}$ konnten wir durch Chromatographie an DEAE-Sephadex eine weitere Fraktion $\mathrm{A}_{2} \mathrm{~F}_{1}$ gewinnen, die bei der Ionenstärke 0,15 die Beweglichkeit von L-Zellen nicht verlangsamte, jedoch zusammen mit $\mathrm{A}_{1} \mathrm{~F}_{1}$, das bei dieser Ionenstärke nicht wirksam war, membranaktiv war. Dieser Befund führte zu der Annahme, daß zumindest zwei verschiedene Proteine für die Wirksamkeit des Serums auf die elektrophoretische Beweglichkeit von L-Zellen notwendig sind; eine starke Konzentrationserhöhung

24 W. Piper u. G. Ruhenstroth-Bauer, Klin. Wschr. 34, 11 [1956]. von $A_{1} F_{1}$ kann jedoch den Effekt der Ionenstärke ausgleichen. Auch bei Inkubation der Zellen mit Serum ist vorwiegend die Adsorption der wirksamen Ig-G-Globulinfraktion $A_{1} F_{1}$ für die Verlangsamung der elektrophoretischen Beweglichkeit der Zellen verantwortlich, wie die Untersuchung des Uberstandes nach Waschen in physiologischer Kochsalzlösung zeigt.

Die Thermolabilität der verlangsamenden Wirkung im Serum läßt sich durch unspezifische Aggregation zwischen thermolabilen Serumproteinen und elektrophoretisch membranaktivem Ig-G-Globulin erklären. Auch der Aktivitätsverlust des Serums nach Dialyse gegen ein ionenschwaches Medium könnte auf einem ähnlichen Aggregationsmechanismus beruhen.

Frl. B. DÜRR und Herrn L. Uher danken wir für wertvolle technische Assistenz.

\title{
On Metastable States of Carotenoids in Primary Events of Photosynthesis
}

\author{
- Registration by repetitive ultra-short-flash photometry -
}

Ch. WolfF and H. T. WitT

Max-Volmer-Institut, I. Institut für Physikalische Chemie, Technische Universität Berlin

(Z. Naturforschg. 24 b, 1031-1037 [1969] ; eingegangen am 10. März 1969)

\begin{abstract}
A repetitive ultra-short-flash photometer is described which can resolve absorption changes of $0,01 \%$ in the time range of $10^{-7} \mathrm{sec}$. With this instrument the following results have been obtained. Air-saturated suspensions of photosynthetic systems show light induced absorption changes with a decay time of $\tau_{1 / 2} \cong 3 \cdot 10^{-6}$ sec. The properties of absorption changes indicate that they are caused by a metastable state.

The difference spectrum of the changes are characterized by peaks at $430,460,490$ and $520 \mathrm{~nm}$. No absorption changes are observed in the red region! Therefore the metastable state is formed by carotenoids.

Excitation of chlorophyll sensitizes the formation of the metastable state of the carotenoid. Therefore a transfer of energy from chlorophyll to carotenoid has to be assumed.

The desactivation of the metastable state represents probably an energy valve reaction.
\end{abstract}

1. 1958 we reported on a special type of absorption changes in photosynthesis with a decay time of $\sim 10^{-5}$ sec. The difference spectrum shows a negative peak at $430 \mathrm{~nm}$ with a shoulder at $460 \mathrm{~nm}$ (in chlorella also at $490 \mathrm{~nm}$ ) and a positive peak at $520 \mathrm{~nm}^{1,2}$. We called it "type 1 ".

1 H. T. Witt, R. Moraw, and A. Müller, Z. physik. Chem. N.F. 14, 127 [1958]; H. T. WITT, R. MORAW, and A. MÜlleR, Z. Naturforschg. 13 b, 822 [1958].

2 R. Moraw and H. T. Witt, Z. physik. Chem. N.F. 29, 1 [1961].
2. Type 1 occurs at temperatures between $\leqq-160^{\circ} \mathrm{C}$ and $+60{ }^{\circ} \mathrm{C}^{3}$.

3. Type $\mathrm{l}$ can be quenched by paramagnetic gases $\left(\mathrm{O}_{2}, \mathrm{NO}\right)^{3}$.

4. Type 1 increases also above the saturating light energy of photosynthesis $1,3,4$.

3 G. Zieger, A. Müller, and H. T. Witt, Z. physik. Chem. N.F. 29, 13 [1961].

${ }^{4}$ R. Moraw, Thesis, Universität Marburg 1960. 